\title{
DESEMPENHO DE VARIEDADES DE SORGO DUPLAAPTIDÃO SUBMETIDAS A DIFERENTES LÂMINAS DE IRRIGAÇÃO COM ÁGUA SALINA
}

\author{
ANDRÉA RAQUEL FERNANDES CARLOS DA COSTA', JOÃO PAULO NUNES COSTA², \\ JOSÉ FRANCISMAR DE MEDEIROS ${ }^{2}$, MAX VENÍCIUS TEXEIRA DA SILVA ${ }^{2}$ \\ e VITOR ABEL DA SILVA LINO²
}

${ }^{1}$ Conselho Nacional de Desenvolvimento Cientifico e Tecnológico, CNPQ, Brasilia, DF, Brasil, andrearaquel19@hotmail.com

${ }^{2}$ Universidade Federal Rural do Semi-árido, UFERSA, Mossoró, RN, Brasil,

jppoty@hotmail.com,jfmedeir@ufersa.edu.br,max_agro_88@hotmail.com,vabel55@gmail.com

Revista Brasileira de Milho e Sorgo, v.18, n.3, p. 417-428, 2019

\begin{abstract}
RESUMO - Objetivou-se avaliar a produtividade de grãos e de colmos, e a qualidade do caldo de cultivares de sorgo dupla aptidão, submetidas a diferentes concentrações salinas da água e lâminas de irrigação. Os fatores estudados foram arranjados em parcelas subdivididas ( $4 \times 3) \times 3$, sendo as quatro concentrações salinas ( $\mathrm{CE}=0,8 ; 2,4 ; 3,4$; e 4,8 dS m$\left.~^{-1}\right)$ e as três lâminas ( 306,378 e $490 \mathrm{~mm}$ ) em fatorial nas parcelas e as três cultivares nas subdivididas (BRS 506, IPA 2502 e Ponta Negra), e delineados em blocos casualizados com quatro repetições. O experimento foi conduzido por 120 dias, e nesse período as plantas foram avaliadas quanto a produção de grãos, massa seca e fresca do colmo e ${ }^{\circ}$ Brix do caldo. Observou-se que a redução de $23 \%$ da lâmina considerada potencial para a cultura não prejudicou o rendimento total e de colmos das cultivares de sorgo BRS 506 e Ponta Negra. A cultivar de sorgo BRS 506 é mais sensível a salinidade, porém apresenta os maiores teores de sólidos solúveis, sendo a mais indicada para produção de etanol e açúcar. Não houve efeito significativo das lâminas de irrigação e da salinidade da água de irrigação sobre a massa de 100 grãos e produtividade de grãos das cultivares de sorgo. A cultivar IPA 2502 apresenta o pior rendimento independentemente da lâmina e da salinidade da água de irrigação.
\end{abstract}

Palavras-chave: Sorghum bicolor, salinidade, lâminas de água.

\section{GROWTH OF VARIETIES OF DOUBLE APTITUDE SORGHUM SUBMITTED TO DIFFERENT IRRIGATION DEPTHS WITH SALINE WATER}

\begin{abstract}
The objective was to evaluate the grains and stalks productivity, and the juice quality of cultivars of double aptitude sorghum submitted to saline concentrations of water and irrigation depths. The factors studied were arranged in subdivided plots $(4 \times 3) \times 3$, with four saline concentrations $\left(\mathrm{CE}=0,8 ; 2,4 ; 3,4 ; \mathrm{e} 4,8 \mathrm{dS} \mathrm{m}^{-1}\right)$ and three depths slides $(306,378 \mathrm{e} 490 \mathrm{~mm})$ in factorial and the three cultivars in the subdivided plots, delineated in randomized blocks with four replicates. The experiment was conducted for 120 days and during this period were evaluated grains production, dry and fresh stalk mass and juice ${ }^{\circ}$ Brix. It was observed that the $23 \%$ reduction of the water depth, considered as potential for the crop, did not affect the total and stalks productivity of sorghum cultivars BRS 506 and Ponta Negra. The cultivar BRS 506 is more sensible to salinity, but has the highest soluble solids content, being the most indicated for ethanol and sugar production. There wasn't significant effect of irrigation depths and irrigation water salinity on the mass of 100 grain and grain productivity of sorghum cultivars. The cultivar IPA 2502 present the worst yield independently of the depth and water salinity.
\end{abstract}

Key words: Sorghum bicolor, salinity, water depths. 
O aumento da população mundial em dimensões aceleradas tem ocasionado preocupações com a disponibilidade de alimentos, água e energia para suprir as demandas crescentes (Saath \& Fachinello, 2018).

A escassez de água tem sido uma preocupação ao longo da história da humanidade e, a partir da última década do século XX este problema tornou-se mais evidenciado devido ao crescimento populacional e à melhoria das condições de vida, aumentando assim, a demanda pelo consumo de água (Juan, 2000).

No Brasil, a escassez desse recurso é bastante visível, sobretudo na região Nordeste, que ocupa $18 \%$ do território brasileiro. Segundo Soares (2006) a escassez de recursos hídricos, qualitativa e quantitativa, é um fato marcante no Nordeste brasileiro, caracterizado por períodos de seca prolongados afetando a disponibilidade deste recurso. As águas subterrâneas na região semiárida são alternativas de abastecimento em épocas de estiagem. Isto porque os graves problemas de escassez, com fortes impactos econômicos e sociais decorrentes, podem ser reduzidos mediante a exploração de recursos subterrâneos, mesmo reconhecendo-se que suas águas muitas vezes são salobras (Demétrio et al., 1993).

O uso de água salina na agricultura pode ser considerado alternativa importante em regiões com baixa disponibilidade hídrica, além disto, é um dos grandes desafios de pesquisadores e produtores agrícolas, em virtude principalmente da escassez de água de boa qualidade, buscando obter produtividades economicamente viáveis e produtos com qualidade, utilizando água de qualidade inferior (Costa et al., 2012).

Algumas alternativas têm possibilitado o uso de águas salinas na agricultura irrigada, dentre estas: cultivo de espécies halófitas forrageiras ou leguminosas; maior eficiência no manejo da adubação; rotação de culturas e irrigação com misturas de águas de diferentes concentrações de sais.

Assim, a utilização de água salina pode ser considerada opção para irrigação, porém é fundamental escolha de culturas adaptadas às condições edáficas destas regiões, já que o estresse salino pode inibir o crescimento das plantas, por reduzir o potencial osmótico da solução do solo e consequentemente o potencial hídrico, restringindo a disponibilidade de água, além de provocar acumulação excessiva de íons nos tecidos vegetais (Silva et al., 2008).

O desequilíbrio nutricional causado pela salinidade ocorre, devido à redução na absorção de nutrientes essenciais à planta devido à competição na absorção e transporte, às alterações estruturais na membrana e à inibição da atividade de várias enzimas do metabolismo (Aragão et al., 2010).

Para Santana et al. (2007), as culturas respondem diferentemente à salinidade podendo ser desde sensíveis a altamente tolerantes ao ambiente salino. Em geral, plantas tolerantes à salinidade realizam ajustes osmóticos por meio da acumulação de solutos osmoticamente ativos, permitindo a absorção de água sob essas condições. Desta forma, a tolerância da cultura à salinidade pode variar entre espécies e cultivares da mesma espécie, além de outros fatores como tipo de sal, tempo de exposição ao estresse, estágio fenológico, fatores edafoclimáticos e interação entre eles (Munns \& Tester, 2008).

No Nordeste brasileiro o sorgo tem sido o cereal mais indicado por apresentar adaptabilidade às condições dos estresses abióticos existentes no semiárido, sendo considerado moderadamente tolerante a salinidade (Dias \& Blanco, 2010). Desta maneira, o sorgo apresenta-se como alternativa para a produção de material forrageiro, grãos, etanol e açúcar em regiões áridas e semiáridas, em que o estresse hídri- 
co e salino limita o desenvolvimento da maioria das culturas.

Em regiões onde a água é escassa, a otimização da irrigação também é um aspecto de suma importância e como o sorgo é uma cultura que apresenta tolerância a condições de estresse hídrico uma irrigação ótima implicaria em menores lâminas aplicadas em relação à irrigação plena, sem que haja perdas significativas de produção (Costa \& Medeiros, 2017).

Desse modo, as águas salinas como alternativa para a irrigação de sorgo no semiárido brasileiro fica condicionada a tolerância da cultura à salinidade, a mistura dessas águas com água de baixa concentração de sais, visando incentivar a inserção dessas águas na produção vegetal em regiões que sofrem com secas prolongadas e ao manejo da irrigação com vistas a otimização do uso da água e ao controle da salinização destas áreas, para que o produtor possa aumentar sua produção utilizando os recursos hídricos de maneira sustentável (Silva et al., 2014).

Nesse sentido, objetivou-se por meio desta pesquisa avaliar a produtividade de grãos e de colmos, e a qualidade do caldo de cultivares de sorgo dupla aptidão, submetidas a diferentes concentrações salinas da água de irrigação e lâminas de irrigação.

\section{Material e Métodos}

O experimento foi realizado no município de Mossoró-RN, Brasil, cujas coordenadas geográficas são $5^{\circ} 10$ '20" de latitude Sul, $37^{\circ} 18^{\prime} 10^{\prime}$ " de longitude Oeste e $70 \mathrm{~m}$ de altitude.

O solo da área experimental foi classificado como Argissolo Vermelho-Amarelo latossólico conforme EMBRAPA (2013). Na Tabela 1, encontramse os valores das análises do solo realizadas antes da instalação do experimento e da água utilizada do poço profundo. O solo do local para a camada de $0-20 \mathrm{~cm}$ apresenta densidade do solo igual a $1,53 \mathrm{~g} \mathrm{~cm}^{-3}$, densidade de partículas de $2,64 \mathrm{~g} \mathrm{~cm}^{-3}$ com conteúdo de areia, silte e argila de $82 \%, 4 \%$ e $14 \%$, respectivamente.

O preparo do solo foi realizado 15 dias antes da instalação do experimento, e consistiu de uma aração, seguida por uma gradagem, abertura dos sulcos de plantio e realização da adubação de fundação. A adubação do solo foi realizada parte em fundação e parte por meio da fertirrigação, utilizando-se as recomendações de Ipa (2008). Para o N a dose padrão foi de $30 \mathrm{~kg} \mathrm{ha}^{-1}$, utilizando-se como fonte a ureia via fertirrigação. Para $\mathrm{K}\left(\mathrm{K}_{2} \mathrm{O}\right)$ e $\mathrm{P}\left(\mathrm{P}_{2} \mathrm{O}_{5}\right)$ as doses foram

Tabela 1. Características químicas do solo e da água de irrigação.

Solo (Profundidade 0-20 cm)

\begin{tabular}{|c|c|c|c|c|c|c|c|c|c|}
\hline $\mathrm{P}$ & & & $\mathrm{Ca}^{2+}$ & $\mathrm{Mg}^{2+}$ & $\mathrm{Na}^{+}$ & Soma de Bases & $\mathrm{Al}^{3+}$ & \multirow{2}{*}{\multicolumn{2}{|c|}{$\mathrm{pH}\left(\mathrm{H}_{2} \mathrm{O}\right)$}} \\
\hline $\mathrm{mg} \mathrm{kg}^{-1}$ & \multicolumn{7}{|c|}{$\left(\mathrm{cmol}_{\mathrm{c}} \mathrm{dm}^{-3}\right)$} & & \\
\hline 30 & & & 3,20 & 1,00 & 0,31 & 4,79 & 0,05 & \multicolumn{2}{|c|}{6,00} \\
\hline \multicolumn{10}{|c|}{ Análise da água (Poço Profundo) } \\
\hline $\mathrm{CE}$ & $\mathrm{Ca}^{2+}$ & $\mathrm{K}^{+}$ & $\mathrm{Mg}^{2+}$ & $\mathrm{Na}^{+}$ & $\mathrm{Cl}^{-}$ & $\mathrm{HCO}_{3}^{-}$ & \multirow{2}{*}{$\mathrm{pH}$} & \multirow{2}{*}{ RAS } & \multirow{2}{*}{$\mathrm{RAS}_{\mathrm{aj}}$} \\
\hline $\mathrm{dS} \mathrm{m}^{-1}$ & \multicolumn{6}{|c|}{$\left(\mathrm{mmol}_{\mathrm{c}} \mathrm{dm}^{-3}\right)$} & & & \\
\hline 0,8 & 3,1 & 0,44 & 0,9 & 2,16 & 2,4 & 4,6 & 8,8 & 1,97 & 1,80 \\
\hline
\end{tabular}


determinadas de acordo o teor desses elementos no solo, com aplicação de $60 \mathrm{~kg} \mathrm{ha}^{-1}$ de $\mathrm{K}_{2} \mathrm{O}$ e $30 \mathrm{~kg}$ ha $^{-1}$ de $\mathrm{P}_{2} \mathrm{O}_{5}$, utilizando-se como fontes o cloreto de potássio e o superfosfato simples, via fertirrigação e fundação, respectivamente.

Os tratamentos estudados foram constituídos de três fatores, concentração de sais da água de irrigação $\left(0,8 ; 2,4 ; 3,4 ;\right.$ e $4,8 \mathrm{dS} \mathrm{m}$ m$\left.^{-1}\right)$, lâminas de irrigação (306, 378 e $490 \mathrm{~mm}$ ) e cultivares de sorgo (BRS 506, IPA 2502, e Ponta Negra), arranjados em parcelas subdivididas $(4 \times 3) \times 3$, sendo as quatro concentrações salinas e as três lâminas em fatorial nas parcelas e as três cultivares nas subdivididas, e delineados em blocos completamente casualizados com quatro repetições.

A água de menor concentração salina $(0,8 \mathrm{dS}$ $\mathrm{m}^{-1}$ ) foi proveniente de poço artesiano profundo e a água de maior concentração $\left(4,8 \mathrm{dS} \mathrm{m}^{-1}\right)$, baseada na tolerância à salinidade da cultura do sorgo para um rendimento potencial de $50 \%$, de acordo com Ayers \& Westcot (1999), produzida previamente com a adição de sais $\left(\mathrm{NaCl}, \mathrm{CaCl} .2 \mathrm{H}_{2} \mathrm{O}\right.$ e $\left.\mathrm{MgSO}_{4} \cdot 7 \mathrm{H}_{2} \mathrm{O}\right)$, para ficar com uma proporção molar de cargas de 7:2:1 de $\mathrm{Na}, \mathrm{Ca}$ e $\mathrm{Mg}$, que representa a composição média das águas salobras do semiárido nordestino. As outras duas concentrações de sais $\left(2,4\right.$ e 3,4 $\left.\mathrm{dS} \mathrm{m}^{-1}\right)$ da água foram obtidas da mistura dessas duas águas, sendo monitoradas diariamente, com auxílio de um condutivímetro portátil.

O fator lâminas de irrigação foi determinado a partir de estimativas da evapotranspiração da cultura (80, 98 e 127\%) utilizando-se o método de PenmanMonteith, proposto pela FAO (Allen et al., 2006). O sistema de irrigação utilizado no experimento foi o gotejamento, para obtenção das diferentes lâminas utilizou-se mangueiras com espaçamentos entre gotejadores $(20,30$ e $40 \mathrm{~cm})$ e vazões diferentes $(1,2$,
1,6 e 2,0 $\mathrm{L} \mathrm{h}^{-1}$ ), de modo a proporcionar volumes diferentes por área.

As irrigações eram realizadas diariamente, com base na evapotranspiração máxima da cultura (ET), que foi estimada multiplicando-se a evapotranspiração de referência (ETo pelo coeficiente de cultura $\left(\mathrm{K}_{\mathrm{c}}\right)$, conforme método proposto pela FAO 56 (Allen et al., 2006), aplicando-se a metodologia do Kc dual, usando Kc basais de 0,15; 0,95 e 0,35, respectivamente, para as fases fenológicas inicial, intermediária e para o final do ciclo, adotando-se como eficiência de irrigação para calcular a lâmina bruta de irrigação o efeito do coeficiente de uniformidade de $95 \%$, sendo esta lâmina adotada para a lâmina intermediária $(100 \%)$.

$\mathrm{A} \mathrm{ET}_{\mathrm{o}}$ foi determinada a partir de dados coletados em uma estação meteorológica localizada próxima ao local do experimento.

A cultura utilizada no experimento foi o sorgo (Sorghum bicolor (L.) Moench). O plantio foi realizado manualmente, colocando-se cinco sementes por cova, com desbaste 15 dias após a semeadura, deixando-se três plantas por cova, no espaçamento em fileira dupla $1,2 \times 0,3 \times 0,20 \mathrm{~m}$, com espaçamento médio de $0,75 \mathrm{~m}$ entre fileiras e $0,20 \mathrm{~m}$ entre plantas. As unidades experimentais foram constituídas de duas fileiras duplas de sete metros, sendo as fileiras externas de cada unidade a bordadura, totalizando uma área útil de $3,2 \mathrm{~m}^{2}$, e um total de 144 parcelas experimentais.

As cultivares de sorgo escolhidas para serem estudadas foram BRS 506, IPA 2502 e Ponta Negra. A cultivar do IPA 2502 destaca-se como sendo uma cultivar promissora, por ter um bom rendimento de panícula como também de forragem, tendo boa adaptabilidade no estado do Rio Grande do Norte. A cultivar Ponta Negra se aproxima mais do ideal para as 
condições edafoclimáticas da região. Já a cultivar BRS 506, embora muito rica em sacarose, ainda não se conhece sua adaptabilidade a região.

A produtividade total e de colmos foi avaliada por meio da pesagem total do material vegetal (folhas, cachos e colmos) e dos colmos da área útil no momento da colheita, com o auxílio de uma balança digital portátil com gancho com capacidade para pesar até $50 \mathrm{~kg}$ e os valores expressos em $\mathrm{Mg} \mathrm{ha}^{-1}$.

Devido aos ataques iminentes de pássaros para se alimentar dos grãos, em cada parcela útil, logo após o surgimento das panículas, protegeu-se 12 inflorescências com sacos de papel, as quais foram utilizadas para se estimar o rendimento de massa seca e fresca de panícula e de grãos.

Para obtenção dos dados de massa seca foi realizada, na colheita, coleta da parte aérea de quatro plantas de cada parcela experimental. A parte aérea da planta foi separada em folhas, inflorescências e colmos. Após ser separado, esse material foi pesado para determinação da massa verde total. Em seguida, foram retiradas amostras dos respectivos materiais frescos e colocadas em estufa de circulação forçada mantida à temperatura de $65^{\circ} \mathrm{C}$, até atingirem massa constante, para obtenção da massa seca. Levando em consideração a massa verde da planta e a massa seca existente nas diferentes partes da planta, quantificouse o teor de massa seca em cada parte da planta (folhas, inflorescências e colmos) que se multiplicando pela massa fresca das plantas colhidas na área útil da parcela estimou-se a produção total por parcela e depois determinou-se a produtividade, sendo os valores expressos em $\mathrm{Mg} \mathrm{ha}^{-1}$.

$\mathrm{O}^{\circ}$ Brix foi determinado a partir do caldo extraído da amostragem do colmo de cada parcela experimental, utilizando-se refratômetro digital Autopol 589, (Tecnal).
Os dados foram interpretados por meio de análises de variância, teste de médias de Tukey a 5\% de probabilidade e de regressão, utilizando-se para tanto o Sistema de Análises Estatísticas e Genéticas (SAEG versão 9.0).

\section{Resultados e Discussão}

Observou-se efeito significativo da interação entre lâminas de irrigação (L) e cultivares de sorgo (C) sobre a produção total e de colmos frescos da cultura do sorgo. Verificou-se também, efeito significativo da interação entre salinidades da água de irrigação (S) e cultivares de sorgo (C) sobre a produção total, de colmos frescos, massa seca de colmos e ${ }^{\circ}$ Brix aos níveis de significância de 5\% de probabilidade (Tabela 2).

Avaliando-se a produtividade total de massa verde e de colmos em função das lâminas de irrigação para as diferentes cultivares de sorgo (Figura 1A e B), verificou-se redução linear na produtividade total $\mathrm{e}$ de colmos com o aumento das lâminas de irrigação para as cultivares BRS 506 e Ponta Negra. Os valores máximos de produtividade total (57 e 43,3 $\mathrm{Mg} \mathrm{ha}^{-1}$ ) e de colmos (37,8 e 32,9 $\left.\mathrm{Mg} \mathrm{ha}^{-1}\right)$ foram verificados na lâmina $306 \mathrm{~mm}$, havendo redução de 5 e $7 \%$ na produtividade total e de $6 \%$ na produtividade de colmos quando irrigadas com uma lâmina de $378 \mathrm{~mm}$ (lâmina potencial) para as cultivares Ponta Negra e BRS 506, respectivamente. Essa redução na produtividade se deve a perda de nutrientes pela lavagem do solo no sentido vertical com o excesso de irrigação, carregando os nutrientes para as camadas mais profundas do perfil do solo, fora do alcance das raízes (Silva, 2012), assim, o excesso de água no solo, provoca redução do desenvolvimento vegetal, em função de desequilíbrios nutricionais provocados. 
Tabela 2. Resumo da ANAVA e valores médios de massa de 100 grãos, produtividade de grãos, produtividade total e de colmos frescos, produtividade de massa seca total e de colmos e ${ }^{\circ}$ Brix de cultivares de sorgo (BRS 506, IPA 2502 e Ponta Negra), em função das lâminas de água (L) e salinidades da água de irrigação (S).

\begin{tabular}{|c|c|c|c|c|c|c|c|c|}
\hline Fontes de variação & GL & M100GR12 & PRODGR & PRODT & PRODC & PRODMST & PRODMSC & BRIX \\
\hline & & \multicolumn{7}{|c|}{ Estatística F } \\
\hline BLOCO & 2 & $0,42^{\mathrm{ns}}$ & $0,59^{\text {ns }}$ & $0,04^{\mathrm{ns}}$ & $0,38^{\mathrm{ns}}$ & $2,41^{\mathrm{ns}}$ & $0,13^{\text {ns }}$ & $0,46^{\mathrm{ns}}$ \\
\hline LAM & 2 & $0,64^{\mathrm{ns}}$ & $1,36^{\mathrm{ns}}$ & $2,40 * *$ & $2,22^{\mathrm{ns}}$ & $0,50^{\mathrm{ns}}$ & $2,27^{\mathrm{ns}}$ & $1,48^{\mathrm{ns}}$ \\
\hline SAL & 3 & $0,75^{\mathrm{ns}}$ & $0,17^{\mathrm{ns}}$ & $0,93^{\mathrm{ns}}$ & $1,46^{\mathrm{ns}}$ & $1,53^{\mathrm{ns}}$ & $1,22^{\mathrm{ns}}$ & $0,93^{\mathrm{ns}}$ \\
\hline $\mathrm{LAM}^{*} \mathrm{SAL}$ & 6 & $0,21^{\mathrm{ns}}$ & $0,58^{\mathrm{ns}}$ & $0,73^{\mathrm{ns}}$ & $0,57^{\mathrm{ns}}$ & $0,41^{\mathrm{ns}}$ & $1,30^{\mathrm{ns}}$ & $0,41^{\mathrm{ns}}$ \\
\hline $\operatorname{ERRO}(a)$ & 22 & --- & --- & --- & --- & --- & --- & --- \\
\hline CULTIVAR & 2 & $136,55^{* *}$ & $257,15^{* *}$ & $276,05 * *$ & $301,42 * *$ & $159,83 * *$ & $136,42 * *$ & $458,99 * *$ \\
\hline LAM*CULT & 4 & $1,39^{\mathrm{ns}}$ & $0,35^{\mathrm{ns}}$ & $2,66 * *$ & $2,27 * *$ & $1,5^{\mathrm{ns}}$ & $1,64^{\mathrm{ns}}$ & $1,41^{\mathrm{ns}}$ \\
\hline SAL*CULT & 6 & $1,64^{\mathrm{ns}}$ & $0,24^{\mathrm{ns}}$ & $1,60^{\mathrm{ns}}$ & $1,32^{\mathrm{ns}}$ & $2,20^{\circ}$ & $2,40 *$ & $2,63 *$ \\
\hline LAM*SAL*CULT & 12 & $1,16^{\mathrm{ns}}$ & $0,48^{\text {ns }}$ & $1,20^{\mathrm{ns}}$ & $1,07^{\mathrm{ns}}$ & $1,21^{\mathrm{ns}}$ & $1,28^{\mathrm{ns}}$ & $0,97^{\mathrm{ns}}$ \\
\hline ERRO(b) & 48 & --- & --- & --- & --- & --- & --- & --- \\
\hline Média & & 2,50 & 4,58 & 40,53 & 27,00 & 11,40 & 4,85 & 12,47 \\
\hline C.V (a) & & 6,07 & 22,42 & 24,10 & 26,82 & 22,61 & 28,32 & 11,18 \\
\hline C.V (b) & & 11,08 & 22,43 & 11,50 & 13,57 & 13,96 & 19,62 & 11.07 \\
\hline
\end{tabular}

${ }^{\mathrm{ns}}$ não significativo, ${ }^{*}$ significativo a $5 \%,{ }^{*}$ significativo a $1 \%{ }^{\circ}{ }^{\circ}$ significativo a $10 \%$ de probabilidade pelo teste $\mathrm{F}$.

A redução da produtividade de sorgo com o aumento do volume de água aplicado durante a irrigação comprova o quão resistente a cultura é as condições de déficit hídrico, a redução de $23 \%$ da lâmina considerada potencial para a cultura não prejudicou o rendimento total e de colmos das cultivares de sorgo BRS 506 e Ponta Negra e não influenciou significativamente o rendimento total e de colmos da cultivar IPA 2502, apresentando valores médios de 27,9 e 15,1 $\mathrm{Mg} \mathrm{ha}^{-1}$, respectivamente.

Assim como em outras culturas, tanto o excesso (alagamento) quanto a falta de água (seca ou déficit hídrico) no solo afeta o desenvolvimento do sorgo. Porém, o sorgo requer menos água para se desenvolver quando comparado a outros cereais. Quando comparado ao milho, por exemplo, o sorgo produz mais sobre estresse hídrico, murcha menos e é capaz de se recuperar de murchas prolongadas. Isso acontece devido a cultura apresentar dois mecanismos de resistência a seca, o escape e a tolerância. O escape é devido ao sistema radicular profundo e ramificado, o qual é eficiente na extração de água do solo. Já a tolerância está relacionada ao nível bioquímico. A planta diminui o metabolismo, murcha e tem um poder de recuperação quando o estresse é interrompido.

Isso ocorre devido a cultura do sorgo possuir mecanismos fisiológicos que a torna mais tolerante ao estresse hídrico. Nesse sentido, a produção de sorgo vem ganhando destaque em regiões onde há baixa precipitação e chuvas irregulares, devido à sua facilidade de cultivo, resistência à seca, rapidez no estabelecimento e no crescimento. A cultivar de sorgo 
$1 \mathrm{~A}$.

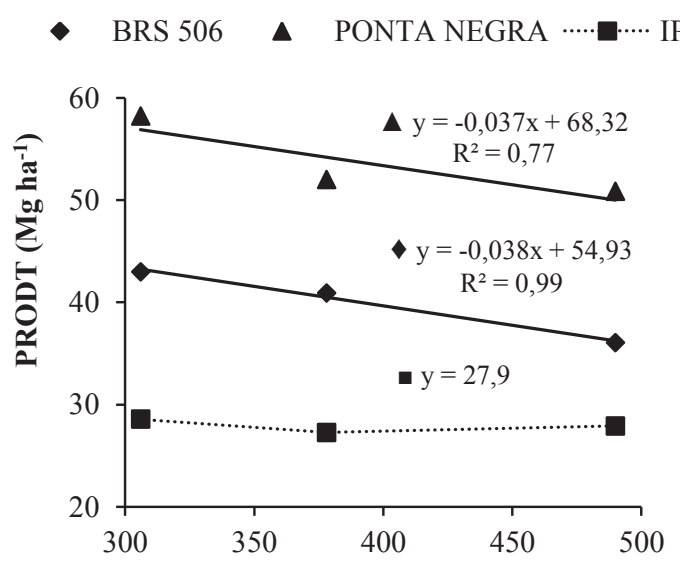

$1 \mathrm{~B}$.

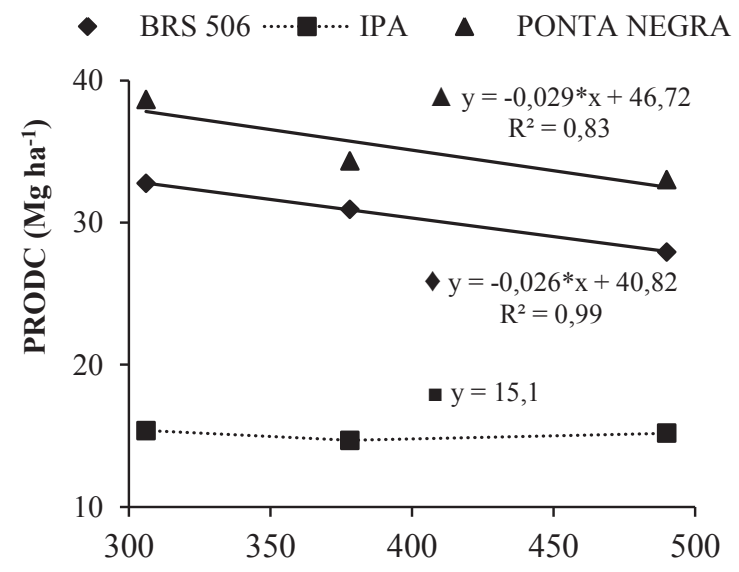

Lâminas de irrigação (mm)

Figura 1. Produtividade total (A) e de colmos frescos (B) de cultivares de sorgo (BRS 506, IPA 2502 e Ponta Negra), em função das lâminas de irrigação.

Ponta Negra, por exemplo, é uma das mais plantadas na região Nordeste por apresentar mais adaptabilidade às condições dos estresses abióticos existentes no semiárido (Rodrigues, 2010).

Quanto ao efeito das concentrações salinas da água de irrigação sobre produtividade de massa seca de colmos (PRODMSC), observou-se efeito significativo apenas para a cultivar BRS 506, ajustando-se equação linear decrescente (Figura 2). O maior valor de produtividade de massa seca $\left(6,4 \mathrm{Mg} \mathrm{ha}^{-1}\right)$ foi verificado na CEa de $0,8 \mathrm{dS} \mathrm{m}^{-1}$ e o menor $\left(5,0 \mathrm{Mg} \mathrm{ha}^{-1}\right)$ na $\mathrm{CEa}$ de 4,81 dS m${ }^{-1}$ havendo uma redução de 27,5 $\%$ na produtividade de massa seca de sorgo da menor para maior concentração salina da água de irrigação. Para as demais cultivares (IPA 2502 e Ponta Negra) não houve efeito significativo das concentrações salinas sobre o rendimento de massa seca de colmos, apresentando valores médios de produtividade de massa seca de colmos de 2,7 e 6,2 $\mathrm{Mg} \mathrm{ha}^{-1}$, respectivamente.
Devido à variabilidade genética entre as cultivares de sorgo estudadas ocorre uma variação na tolerância à salinidade. O sorgo Ponta Negra por possuir características apropriadas ao semiárido nordestino e apresentar tolerância moderada à salinidade, apresenta-se como alternativa para o aproveitamento de água salina (Vale \& Azevedo, 2013) podendo apresentar elevada produtividade mesmo quando irrigada com água de elevada salinidade.

Já a cultivar de sorgo BRS 506, não existem estudos que comprovem a sua resistência a salinidade da água, com isso, é possível a sua indicação para cultivo irrigado em regiões com pouca disponibilidade de água de baixa salinidade para irrigação, visto que, essa cultivar apresentou produtividade média de massa verde em condições salinas (Figura 3A) semelhante a produtividade média dentro das condições normais de cultivo, que de acordo com Pereira Filho et al. (2013) pode variar de 40 a $60 \mathrm{Mg} \mathrm{ha}^{-1}$, o que contribuiu para uma elevada produção de massa seca 


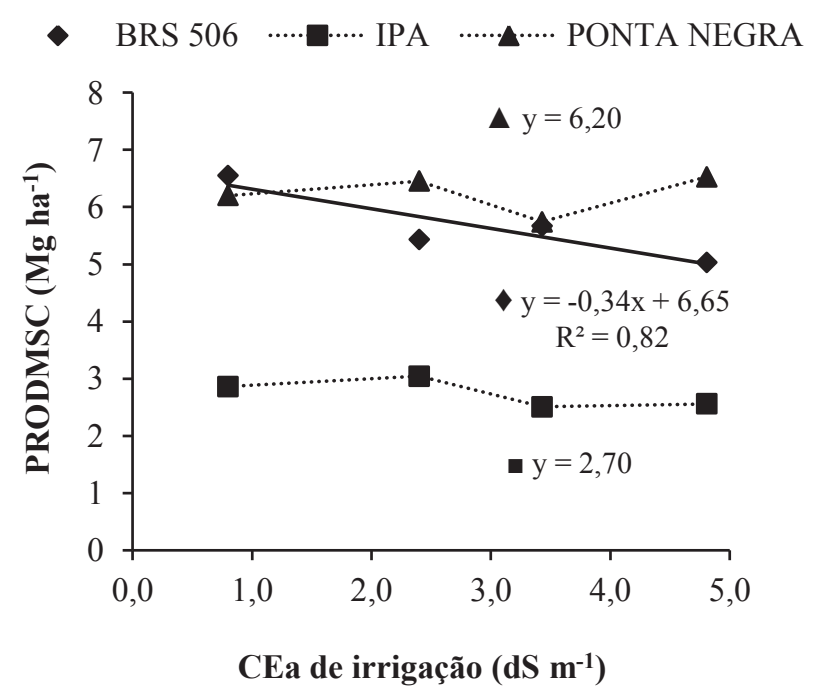

Figura 2 - Produtividade de massa seca de colmos de cultivares de sorgo (BRS 506, IPA 2502 e Ponta Negra), em função das concentrações salinas da água de irrigação.

de colmos, mesmo em condições de alta salinidade da água de irrigação.

No entanto, o efeito da salinidade sobre o desenvolvimento da cultivar de sorgo BRS 506 provavelmente ocorreu devido a diminuição da disponibilidade hídrica no solo, o que ocasiona queda no potencial da água da folha e consequente perda de turgescência e fechamento estomático, o que acarreta redução da fotossíntese e perdas na produção de biomassa (Munns \& Tester, 2008). Alguns estudos demonstram reduções na produção de massa seca em reposta à salinidade, com taxas de perdas variando em função de materiais genéticos e condições ambientes (Lima et al., 2011; Sousa et al., 2012; Feijão et al., 2011).

Em relação a IPA 2502, apesar de ser uma cultivar recomendada para o Semiárido nordestino, visando ao atendimento da demanda forragem/silagem para a pecuária regional, nos períodos secos, observou-se que esta cultivar apresentou menor rendimento em relação as demais, em todas as condições da pesquisa. Apesar disto, apresentou produtividade média $\left(27,9 \mathrm{Mg} \mathrm{ha}^{-1}\right)$, dentro do padrão de produção de biomassa total, que pode variar de 20 a $30 \mathrm{Mg} \mathrm{ha}^{-1}$ (IPA, 2019).

Com relação ao efeito das concentrações salinas da água de irrigação sobre a produtividade total e de colmos das cultivares de sorgo (Figura 3) verificou-se resposta significativa apenas para a cultivar BRS 506, ajustando-se equação linear decrescente. Considerando-se os valores obtidos pelas equações de regressões para a cultivar BRS 506, observou-se que as maiores produtividades total $\left(43,9 \mathrm{Mg} \mathrm{ha}^{-1}\right) \mathrm{e}$ de colmos (33,8 $\left.\mathrm{Mg} \mathrm{ha}^{-1}\right)$ foram obtidas na CEa de 0,8 $\mathrm{dS} \mathrm{m}{ }^{-1}$, enquanto as menores (36,2 e 27,5 $\mathrm{Mg} \mathrm{ha}^{-1}$ ) na CEa de 4,81 dS m${ }^{-1}$, havendo uma redução de 21,5 e 23,1\% da CEa de $0,8 \mathrm{dS} \mathrm{m}^{-1}$ para CEa de $4,81 \mathrm{dS} \mathrm{m}^{-1}$. As cultivares IPA 2502 e Ponta Negra apresentaram valores médios de produtividade total de 27,9 e 53,7 $\mathrm{Mg} \mathrm{ha}^{-1}$ e de colmos de 11,7 e 32,9 $\mathrm{Mg} \mathrm{ha}^{-1}$, respectivamente.

Embora a cultura do sorgo seja classificada como moderadamente tolerante a salinidade, podem ocorrer reduções significativas na produção de massa seca em resposta à salinidade, com taxas de perdas 
$1 \mathrm{~A}$.

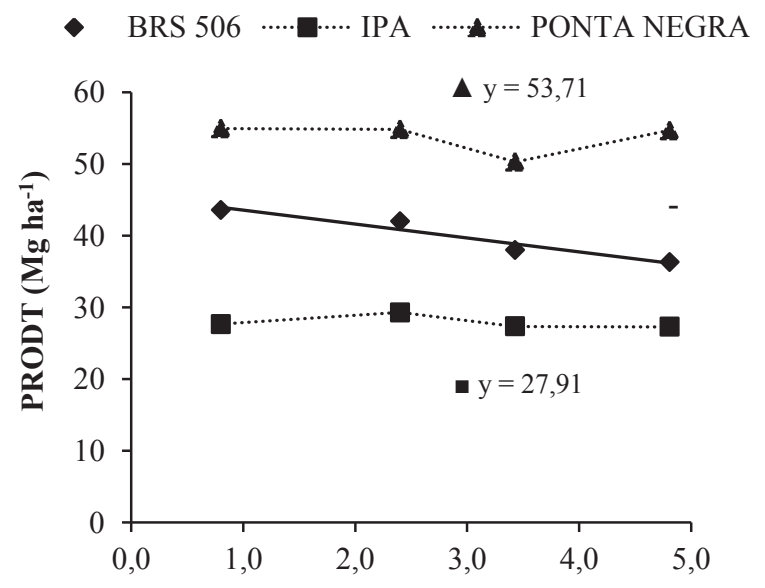

$1 B$.

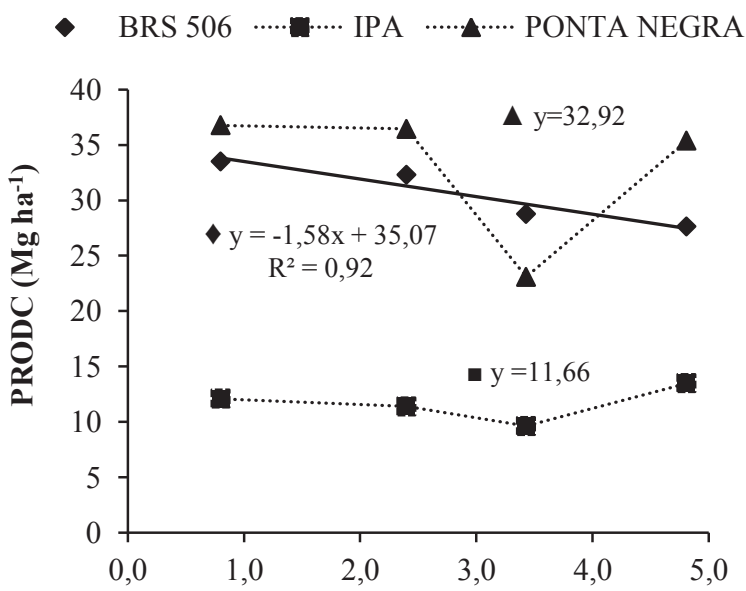

CEa de irrigação $\left(\mathrm{dS} \mathrm{m}^{-1}\right)$

Figura 3. Produtividade total (A) e de colmos frescos (B) de cultivares de sorgo (BRS 506, IPA 2502 e Ponta Negra), em função das concentrações salinas da água de irrigação.

variando em função de materiais genéticos (Coelho et al., 2014). Os efeitos negativos dos sais sobre o crescimento das plantas podem estar associados ao componente de tensão osmótica, provocado pela diminuição do potencial de água no solo e, por conseguinte, pela restrição de absorção de água pelas raízes (Oliveira et al., 2011).

Observou-se que o teor de sólidos solúveis da cultivar Ponta Negra aumentou a partir da CE da água de 2,3 dS m-1, obtendo-se na CEa de 4,81 dS m ${ }^{-1}$ um teor de sólidos solúveis de $12,3 \%$, ou seja, houve um aumento de $17,4 \%$ no teor de sólidos solúveis da $\mathrm{CEa}$ de 2,3 $\mathrm{dS} \mathrm{m}^{-1}$ para a CEa de 4,81 $\mathrm{dS} \mathrm{m}^{-1}$ (Figura 4). A aplicação de água salina melhora a qualidade dos frutos. Com o acréscimo nos níveis de salinidade da água de irrigação os valores de SS aumentam, pois o aumento da concentração salina da água de irrigação reduz a absorção de água pela planta, reduzindo o tamanho do fruto, propiciando consequentemente uma concentração maior de SS no colmo. Esse efeito também foi observado por outros autores, em diferentes culturas, como melão e melancia (Costa, 2013; Mascarenhas et al.,2010) os quais verificaram que os valores de SS aumentam com o acréscimo nos níveis de salinidade da água de irrigação.

Para as cultivares BRS 506 e IPA 2502 não houve efeito significativo da análise de regressão das concentrações salinas da água de irrigação sobre o teor de sólidos solúveis, apresentando valores médios de 17,91 e 8,28\%. Apesar de não ter havido influência da salinidade sobre o ${ }^{\circ}$ BRIX destas cultivares, a cultivar BRS 506, por exemplo, apresentou os maiores teores de sólidos solúveis, teores estes próximos aos encontrados para a cana-de-açúcar, que estão entre 18 e $21{ }^{\circ}$ Brix. Segundo Durães et al. (2012) nesta espécie ocorre variação de 15 a $21^{\circ}$ Brix o que torna a utilização do caldo do sorgo uma alternativa para complementar a produção de etanol nas destilarias do país, isso ocorre provavelmente devido à compartimentalização dos sais no colmo. Assim, apesar da 


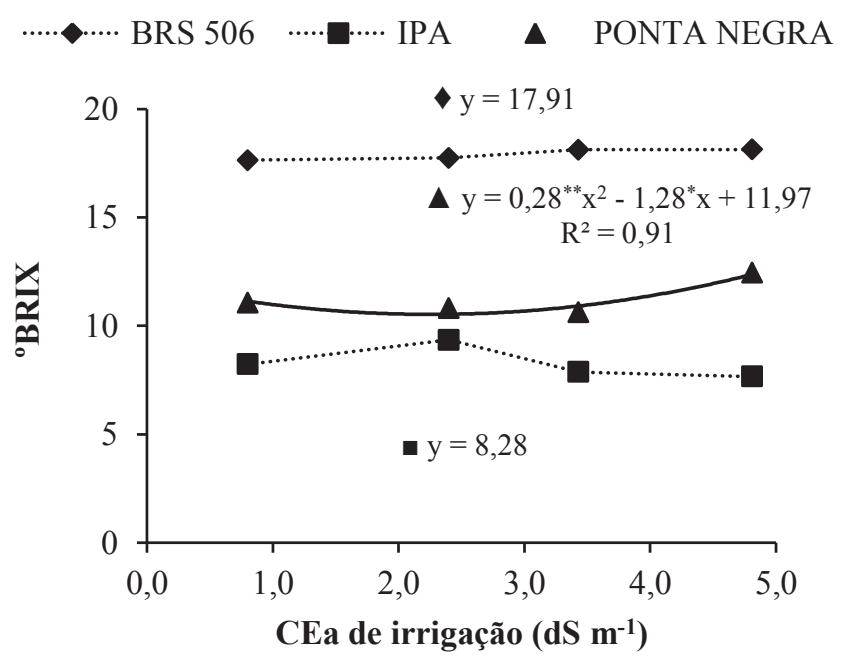

Figura 4 - Teor de sólidos solúveis (\%) de cultivares de sorgo (BRS 506, IPA 2502 e Ponta Negra), em função das concentrações salinas da água de irrigação.

cultivar de sorgo Ponta Negra ter apresentado maior produtividade total e de colmos, a cultivar BRS 506 produziu caldo de melhor qualidade, superando as demais cultivares em termos de aptidão para produção de álcool e açúcar.

\section{Conclusões}

A redução de até $23 \%$ da lâmina considerada potencial para a cultura não prejudica o rendimento de matéria verde e seca das cultivares de sorgo Ponta Negra e IPA 2502. A cultivar de sorgo BRS 506 é mais sensível a salinidade, porém apresenta o maiores teores de sólidos solúveis, sendo a mais indicada para produção de etanol e açúcar. A concentração salina da água de irrigação de até $4,8 \mathrm{dS} \mathrm{m}^{-1}$ não reduz significativamente a produtividade de massa fresca das cultivares de sorgo IPA 2502 e Ponta Negra. A cultivar IPA 2502 apresenta o pior rendimento independentemente da lâmina e da salinidade da água de irrigação.

\section{Agradecimentos}

Ao $\mathrm{CNPq}$ pelo auxílio financeiro necessário para realização deste projeto e pela concessão da bolsa de estudo.

\section{Referências}

ALLEN, R. G.; PEREIRA, L. S.; RAES, D.; SMITH, M. Evapotranspiration del cultivo: guias para a la determinacion de los requeriments de água de los cultivos. Roma: FAO, 2006. 298 p. (FAO. Estudo FAO Irrigação e Drenagem, 56).

ARAGÃO, R. M.; SILVEIRA, J. A. G.; SILVA, E. N.; LOBO, A. K. M.; DUTRA, A. T. B. Absorção, fluxo no xilema e assimilação do nitrato em feijão-caupi submetido à salinidade. Revista Ciência Agronômica, v. 41, n. 1, p. 100-106, 2010. DOI: 10.5935/1806-6690.20100014.

AYERS, R. S.; WESTCOT, D. W. A qualidade da água na agricultura. 2. ed. Campina Grande: UFPB, 1999. 218 p. (FAO. Estudo FAO Irrigação e Drenagem, 29). 
CAVALCANTI, F. J. de A. (Coord.). Recomendações de adubação para o Estado de Pernambuco: $2^{\mathrm{a}}$ a aproximação. 3. ed. rev. Recife: Instituto Agronômico de Pernambuco, 2008. 212 p.

COSTA, A. R. F. C.; MEDEIROS, J. F. Água salina como alternativa para irrigação de sorgo para geração de energia no Nordeste brasileiro. Water Resources and Irrigation Management, v. 6, n. 3, p. 169-177, 2017.

COSTA, A. R. F. C.; MEDEIROS, J. F.; PORTO FILHO, F. de Q.; SILVA, J. S.; COSTA, F. G. B.; FREITAS, D. C. Produção e qualidade de melancia cultivada com água de diferentes salinidades e doses de nitrogênio. Revista Brasileira de Engenharia Agrícola e Ambiental, v. 17, n. 9, p. 947-954, 2013.

DOI: $10.1590 / \mathrm{S} 1415-43662013000900006$.

COSTA, F. G. B.; FERNANDES, M. B.; BARRETO, H. B. F.; OLIVEIRA, A. F. M.; SANTOS, W. O. Crescimento da melancia e monitoramento da salinidade do solo com TDR sob irrigação com águas de diferentes salinidades. Irriga, v. 17, n. 3, p. 327-336, 2012.

DOI: 10.15809/irriga.2012v17n3p327.

COELHO, D. S.; SIMÕES, W. L.; MENDES, A. M. S.; DANTAS, B. F.; RODRIGUES, J. A. S.; SOUZA, M. A. Germinação e crescimento inicial de variedades de sorgo forrageiro submetidas ao estresse salino. Revista Brasileira de Engenharia Agrícola e Ambiental, v.18, n. 1, p. 25-30, 2014. DOI: $10.1590 /$ S1415-43662014000100004.

DEMÉTRIO, J.G.A.; DOHERTY,F.R.;ARAÚJOFILHO,P. F.;SCHEFFER, S.Qualidadedeáguasubterrâneanonordeste brasileiro. In: REUNIÃO ANUAL DA SOCIEDADE BRASILEIRA PARA O PROGRESSO DA CIÊNCIA, 45., Recife, 1993. Anais... Recife: UFPE, 1993. p. 79.

DIAS, N. S.; BLANCO, F. F. Efeitos dos sais no solo e na planta. In: GHEYI, H. R.; DIAS, N. S.; LACERDA, C. F. de. Manejo da salinidade na agricultura: estudo básico e aplicados. Fortaleza: INCT-Sal, 2010. p. 129-140.

DURÃES, F. O. M.; MAY, A.; PARRELlA, L. A. C. Sistema agroindustrial do sorgo sacarino no Brasil e a participação público-privada: oportunidades, perspectivas e desafios. Sete Lagoas: Embrapa Milho e Sorgo, 2012. 77 p. (Embrapa Milho e Sorgo. Documentos, 138).

FEIJÃO, A. R.; SILVA, J. C. B.; MARQUES, E. C.; PRISCO, J. T.; GOMES FILHO, E. Efeito da nutrição de nitrato na tolerância de plantas de sorgo sudão à salinidade. Revista Ciência Agronômica, v. 42, n. 3, p. 675-683, 2011. DOI: 10.1590/S1806-66902011000300014.

INSTITUTO AGRONÔMICO DE PERNAMBUCO. Sorgo sacarino, sem tanino e de dupla finalidade: produção de grãos e silagem. Disponível em: <http://www. ipa.br/pdf/Sorgo\%202502.pdf>. Acesso em: 27 set. 2019.

JUAN, J. A. M. S. Desalación de aguas salobres y de mar: osmose inversa. Madrid: Mundi-Prensa, 2000. 395 p.

LIMA, M. A.; CASTRO, V. F.; VIDAL, J. B.; ENÉASFILHO, J. Aplicação de silício em milho e feijão-de-corda sob estresse salino. Revista Ciência Agronômica, v. 42, n. 2, p. 398-403, 2011.

DOI: $10.1590 /$ S1806-66902011000200019.

MASCARENHAS, F. R.; MEDEIROS, D. C.; MEDEIROS, J. F. de; DIAS, P. M. S.; SOUZA, M. S. M. Qualidade de melão gália cultivado sob diferentes níveis de salinidade. Revista Verde de Agroecologia e Desenvolvimento Sustentável, v. 5, n. 5, p. 171-181, 2010.

MUNNS, R.; TESTER, M. Mechanisms of salinity tolerance. The Annual Review of Plant Biology, v. 59, n. 1, p. 651-681, 2008.

DOI: 10.1146/annurev.arplant.59.032607.092911.

OLIVEIRA, A. B.; ALENCAR, N. L. M.; PRISCO, J. T.; GOMES-FILHO, E. Accumulation of organic and inorganic solutes in $\mathrm{NaCl}$ stressed sorghum seedlings from aged and primed seeds. Scientia Agrícola, v. 68, n. 6, p. 632-637, 2011.

DOI: 10.1590/S0103-90162011000600004.

PEREIRA FILHO, I. A.; PARRELA, R. A. C.; MOREIRA, J. A. A.; MAY, A.; SOUZA, V. F.; CRUZ, J. C. Avaliação 
de cultivares de sorgo sacarino [Sorghum bicolor (1.) Moench] em diferentes densidades de semeadura visando a características importantes na produção de etanol. Revista Brasileira de Milho e Sorgo, v. 12, n. 2, p. 118-127, 2013. DOI: 10.18512/1980-6477/rbms.v12n2p118-127.

RODRIGUES, J. A. S. (Ed.). Cultivo do sorgo. 6. ed. Sete Lagoas: Embrapa Milho e Sorgo, 2010. (Embrapa Milho e Sorgo. Sistema de produção, 2).

SAATH, K. C. de O.; FACHINELLO, A. L. Crescimento da demanda mundial de alimentos e restrições do fator terra no Brasil. Revista de Economia e Sociologia Rural, v. 56, n. 2, p. 195-212, 2018.

DOI: 10.1590/1234-56781806-94790560201.

SANTANA, M. C. B.; BASTOS, E. A.; CARDOSO, M. J.; ANDRADE JÚNIOR, A. S.; TARDIN, F. D.; MENEZES, C. B. Produtividade de grãos e parâmetros fisiológicos de sorgo granífero sob deficiência hídrica e irrigação plena. Revista Brasileira de Milho e Sorgo, v. 16, n. 3, p. 361372, 2017.

DOI: 10.18512/1980-6477/rbms.v16n3p361-372.

SANTANA, M. J.; CARVALHO, J. A.; SOUZA, K. J.; SOUSA, A. M. G.; VASCONCELOS, C. L.; ANDRADE, L. A. B. Efeitos da salinidade da água de irrigação na brotação e desenvolvimento inicial da cana-de-açúcar (Saccharum spp) e em solos com diferentes níveis texturais. Ciência e Agrotecnologia, v. 31, n. 5, p. 1470-1476, 2007. DOI: $10.1590 /$ S1413-70542007000500030.

SANTOS, H. G. dos; JACOMINE, P. K. T.; ANJOS, L. H. C. dos; OLIVEIRA, V. A. de; LUMBRERAS, J. F.; COELHO, M. R.; ALMEIDA, J. A. de; CUNHA, T. J. F.; OLIVEIRA, J. B. de. Sistema brasileiro de classificação de solos. 3. ed. rev. e ampl. Brasília, DF: Embrapa, 2013. $353 \mathrm{p}$.

SILVA, M. O.; FREIRE, M. B. G. S.; MENDES, A. M. S.; FREIRE, F. J.; SOUSA, C. E. S.; GÓES, G. B. Crescimento de meloeiro e acúmulo de nutrientes na planta sob irrigação com águas salinas. Revista Brasileira de Engenharia Agrícola e Ambiental, v. 12, n. 6, p. 593-605, 2008.

DOI: 10.1590/S1415-43662008000600005.

SILVA, L. C. F.; MANIERO, M. A.; CASAGRANDE, J. C.; STOLF, R. Controle de perdas. Cultivar Grandes Culturas, v. 14, p. 6-8, 2012.

SILVA, J. L. A.; MEDEIROS, J. F.; ALVES, S. V.; OLIVEITA, F. A.; SILVA JÚNIOR, M. S.; NASCIMENTO, I. B. Uso de águas salinas como alternativa na irrigação e produção de forragem no semiárido nordestino. Revista Brasileira de Engenharia Agrícola e Ambiental, v. 18, p. 66-72, 2014. Suplemento.

DOI: 10.1590/1807-1929/agriambi.v18nsupps66-s72.

SOARES, T. M.; SILVA, I. J. O.; DUARTE, S. N.; SILVA, E. F. F. Destinação de águas residuárias provenientes de dessalinizadores por osmose reversa. Revista Brasileira de Engenharia Agrícola e Ambiental, v. 10, n. 3, p. 730 737, 2006. DOI: 10.1590/S1415-43662006000300028.

SOUSA, G. G.; MARINHO, A. B.; ALBUQUERQUE, A. H. P.; VIANA, T. V. A.; AZEVEDO, B. M. Crescimento inicial do milho sob diferentes concentrações de biofertilizante bovino irrigado com águas salinas. Revista Ciência Agronômica, v. 43, n. 2, p. 237-245, 2012. DOI: 10.1590/S1806-66902012000200005.

TARDIN, F. D.; ALMEIDA FILHO, J. E.; OLIVEIRA, C. M.; LEITE, C. E. P.; MENEZES, C. B.; MAGALHÃES, P. C.; RODRIGUES, J. A. S.; SCHAFFERT, R. E. Avaliação agronômica de híbridos de sorgo granífero cultivados sob irrigação e estresse hídrico. Revista Brasileira de Milho e Sorgo, v. 12, n. 2, p. 102-117, 2013. DOI: 10.18512/1980-6477/rbms.v12n2p102-117.

VALE, M. B.; AZEVEDO, P. V. Avaliação da produtividade e qualidade do capim elefante e do sorgo irrigados com água do lençol freático e do rejeito do dessalinizador. Holos, ano 29, v. 3, p. 181-195, 2013.

DOI: 10.15628/holos.2013.1383. 